\title{
Soil-to-Plant Transfer Factors of Technetium-99 for Various Plants Collected in the Chernobyl Area
}

\author{
Keiko Tagami and Shigeo Uchida* \\ Office of Biospheric Assessment for Waste Disposal, National Institute of Radiological Sciences, Anagawa \\ 4-9-1, Inage-ku, Chiba-shi, Chiba 263-8555, Japan
}

Received: July 31, 2005; In Final Form: September 30, 2005

Technetium-99 is thought to be highly soluble and rarely adsorbed onto soil, however, its mobility under natural environment is not well known because its scarcity and low levels in environmental samples has limited the available data. In this study, we determined ${ }^{99} \mathrm{Tc}$ contents in 27 plant samples collected in three forest sites in 1994 and 1995 around the Chernobyl area to obtain transfer factors (TFs) of Tc in the soil-plant system under environmental conditions. The samples were leaves of raspberry, strawberry and pink plants, black alder, birch, cowberry and oak trees, and ferns. After chemical separation, ${ }^{99} \mathrm{Tc}$ in the sample was measured by ICP-MS. Tc-95m was used as a yield tracer and the total recovery ranged from 0.48 to 0.92 with an average of 0.76 . The determined ${ }^{99} \mathrm{Tc}$ concentrations in plants ranged from $<0.006$ to $6.0 \mathrm{mBq} \mathrm{g}^{-1}$ (dry weight basis). TF values ranged from $<0.006$ to 0.47 , based on the ${ }^{99} \mathrm{Tc}$ contents of the soil organic layers. The highest TF was found in the leaves of raspberry plants. The observed TFs were much lower than the values of 8.1-2600 compiled by IAEA for grass, fodder and leafy vegetables.

\section{Introduction}

Technetium belongs to the Mn group and it has no stable isotopes. Among its radioactive isotopes, ${ }^{99} \mathrm{Tc}$ is of potential longterm importance in the environment like ${ }^{137} \mathrm{Cs}$. Technetium-99 is a pure beta emitter $\left(E_{\max }=0.29 \mathrm{keV}\right)$ and its radiological half-life is $2.11 \times 10^{5} \mathrm{y}$. It is produced in the fissions of ${ }^{235} \mathrm{U}$ and ${ }^{239} \mathrm{Pu}$ at relatively high r.atios of ca. $6 \%$, which is similar to the values for ${ }^{137} \mathrm{Cs}$ and ${ }^{90} \mathrm{Sr}$. Technetium-99 is widely distributed in the environment as a result of fallout from nuclear weapons testing and discharges from nuclear facilities. Nuclear medical use of ${ }^{99 \mathrm{~m}} \mathrm{Tc}$ (half-life: $6.01 \mathrm{~h}$ ) which decays directly to ${ }^{99} \mathrm{Tc}$ is another source though the ${ }^{99} \mathrm{Tc}$ introduced into the environment via this route is negligible.

For a realistic long-term radiological assessment of the radionuclide, it is necessary to obtain transfer parameters, such as soil-to-plant transfer factors (TFs, concentration in plant/concentration in soil), under natural conditions. Generally, Tc is expected to be mobile in the surface soil environment because of its chemical form, $\mathrm{TcO}_{4}^{-}$, which is the most stable chemical form under natural surface water conditions. ${ }^{1}$ This chemical form is highly soluble in water, rarely adsorbed onto soil particle surfaces, and has a high availability for plants. Indeed, a TF of 5 in the edible parts of common plants (on a wet weight basis) was recommended by the International Atomic Energy Agency (IAEA) for Tc when assessing its behaviour. ${ }^{2}$ Moreover, in Reference 3, soil to grass transfer factor for Tc was reported as 78 (on a dry weight basis), while those for $\mathrm{Sr}$ and $\mathrm{Cs}$ were 0.341.7 and $0.11-0.53$, respectively. This highly mobile chemical form, $\mathrm{TcO}_{4}^{-}$, however, changes with environmental conditions, ${ }^{4-7}$ consequently, TF values would also change. Unfortunately, TF data observed under natural conditions have been limited due to there being only trace levels of ${ }^{99} \mathrm{Tc}$. Obtaining TFs using global fallout ${ }^{99} \mathrm{Tc}$ in agricultural fields is difficult, because the concentration of ${ }^{99} \mathrm{Tc}$ is very low. ${ }^{8}$ Therefore, we focused on the Chernobyl site where ${ }^{99} \mathrm{Tc}$ concentration levels have already been shown to be higher than those from global fallout Tc. ${ }^{9}$

*Corresponding author. E-mail: s_uchida@nirs.go.jp. FAX: +81-43-206-3267.
In this study, we determined the concentrations of ${ }^{99} \mathrm{Tc}$ in plant leaves collected near the Chernobyl site to investigate the transfer of the nuclide in soil-plant systems under natural conditions. The samples were leaves of raspberry, strawberry and pink plants, black alder, birch, cowberry and oak trees, and ferns. Details of ${ }^{99} \mathrm{Tc}$ and ${ }^{137} \mathrm{Cs}$ data for soil samples collected at the same time were reported previously, ${ }^{9}$ thus, the data were used in this study to obtain TFs. Since TFs are usually high in leafy vegetables and grass as reported in Reference 3, leaves of raspberry, strawberry and pink plants are of the most interest in this study for comparison purposes.

\section{Experimental}

2.1. Reagents. Nitric acid used was ultra pure grade (Tama Chemicals, AA-100). A Tc-selective chromatographic resin (Eichrom Industries Inc., TEVA resin) was used for Tc purification. The grain size of the resin was $100-150 \mu \mathrm{m}$ and the volume of the resin in the column was about $2 \mathrm{~mL}$. Deionized water (> 17.6 M 2 ) was used throughout the work. Technetium$95 \mathrm{~m}$, which was obtained from an $\mathrm{Nb}$ foil using the reaction ${ }^{93} \mathrm{Nb}(\alpha, 2 \mathrm{n}){ }^{95 \mathrm{~m}} \mathrm{Tc}$, was applied to determine the recovery of ${ }^{99} \mathrm{Tc}$ in the samples during the chemical separation procedure. The ${ }^{95 \mathrm{~m}} \mathrm{Tc}$ was made at Cycrotron and Radioisotope Center, Tohoku University. In our previous work, we found that this reaction could not produce other long-lived Tc isotopes. ${ }^{10} \mathrm{~A}$ standard ${ }^{99} \mathrm{Tc}$ solution available from Amersham (Solution TCZ.44) was used for calibrating the ICP-MS.

2.2. Plant Samples. Twenty seven plant samples were collected at the Chernobyl site in 1994 and 1995 by the Federal Office for Radiation Protection, Germany, assisted by Moscow State University, Russia, and the Research and Industrial Association "Pripyat", Ukraine. The sampling was carried out in three forests, D1, D3 and K2, around the Chernobyl Nuclear Power Plant. Forests D1 and D3 were $28.5 \mathrm{~km}$ and $26 \mathrm{~km}$ to the south of the reactor, respectively, while forest $\mathrm{K} 2$ was $6 \mathrm{~km}$ to the southeast. The sites D1 and D3 were mixed forests (D1: $50 \%$ oak, $30 \%$ pine, $20 \%$ birch; $55-60$ years old; and D3: $50 \%$ alder, $40 \%$ birch, $10 \%$ pine; $50-75$ years old), while K2 was a pine forest (about 50 years old). ${ }^{11}$ Soil samples were 
also collected at the same sampling sites and the details were reported previously. ${ }^{9}$

The plant samples were leaves of various plants grown in the forests (Table 1). They were separated into three groups, that is, Fern, Herb (raspberry, strawberry and pink), and Tree (black alder, birch, cowberry and oak). After the samples were oven dried at $110{ }^{\circ} \mathrm{C}$, they were thoroughly milled. Then they were transferred to plastic bottles and stored at room temperature.

TABLE 1: Chemical Recovery and Concentration of ${ }^{99} \mathrm{Tc}$ in Plant Samples Collected in Forests within the $30-\mathbf{k m}$ Zone Around the Chernobyl Nuclear Power Plant

\begin{tabular}{|c|c|c|c|c|c|c|}
\hline Group & $\begin{array}{l}\text { Sampling } \\
\text { site }\end{array}$ & Sample & Plan & $\begin{array}{c}\text { Dry } \\
\text { weight } \\
\text { (g) }\end{array}$ & Recovery & $\begin{array}{c}\text { Technetium-99 } \\
\left(\mathrm{mBq} \text { g-dry }{ }^{-1}\right)\end{array}$ \\
\hline \multirow[t]{8}{*}{ Fern } & $\mathrm{K} 2$ & $94 \mathrm{~F}-1 \mathrm{a} *$ & & 1.01 & 0.847 & $2.42 \pm 0.18$ \\
\hline & & $94 \mathrm{~F}-1 \mathrm{~b} *$ & & 1.01 & 0.895 & $2.37 \pm 0.29$ \\
\hline & & $94 \mathrm{~F}-1 \mathrm{c}^{*}$ & & 2.61 & 0.884 & $2.31 \pm 0.26$ \\
\hline & & $95 \mathrm{~F}-1$ & & 4.04 & 0.829 & $0.603 \pm 0.045$ \\
\hline & & $95 \mathrm{~F}-2$ & & 2.00 & 0.749 & $3.79 \pm 0.35$ \\
\hline & D3 & $94 \mathrm{~F}-1$ & & 7.02 & 0.661 & $<0.040$ \\
\hline & & $95 \mathrm{~F}-1$ & & 9.06 & 0.483 & $<0.031$ \\
\hline & & $95 \mathrm{~F}-2$ & & 4.03 & 0.844 & $<0.069$ \\
\hline \multirow[t]{15}{*}{ Herb } & $\mathrm{K} 2$ & 94G-1 & Raspberry & 4.04 & 0.599 & $4.04 \pm 0.42$ \\
\hline & & $94 \mathrm{G}-2 \mathrm{a} *$ & Strawberry & 4.03 & 0.747 & $1.30 \pm 0.17$ \\
\hline & & $94 \mathrm{G}-2 \mathrm{~b}^{*}$ & & 2.07 & 0.852 & $1.57 \pm 0.16$ \\
\hline & & 95G-1 & Pink & 3.99 & 0.739 & $6.02 \pm 0.52$ \\
\hline & & $95 \mathrm{G}-2$ & Raspberry & 17.0 & 0.762 & $3.61 \pm 0.33$ \\
\hline & D1 & 94G-1a* & Strawberry & 6.98 & 0.596 & $0.254 \pm 0.022$ \\
\hline & & $94 \mathrm{G}-1 \mathrm{~b}^{*}$ & & 2.22 & 0.824 & $0.451 \pm 0.090$ \\
\hline & & $94 \mathrm{G}-2$ & Raspberry & 25.1 & 0.563 & $0.222 \pm 0.017$ \\
\hline & & $95 \mathrm{G}-1$ & Raspberry & 35.3 & 0.901 & $0.257 \pm 0.021$ \\
\hline & D3 & $94 \mathrm{G}-1 \mathrm{a}^{*}$ & Strawberry & 10.2 & 0.868 & $0.215 \pm 0.016$ \\
\hline & & $94 \mathrm{G}-1 b^{*}$ & & 1.82 & 0.844 & $0.231 \quad 0.025$ \\
\hline & & $94 \mathrm{G}-1 \mathrm{c} *$ & & 2.81 & 0.823 & $0.192 \quad 0.029$ \\
\hline & & $94 \mathrm{G}-2$ & Raspberry & 20.0 & 0.706 & $0.094 \pm 0.008$ \\
\hline & & $94 \mathrm{G}-3$ & Raspberry & 4.02 & 0.553 & $0.128 \pm 0.011$ \\
\hline & & 95G-1 & Raspberry & 16.2 & 0.915 & $0.016 \pm 0.003$ \\
\hline \multirow[t]{10}{*}{ Tree } & D1 & $94 \mathrm{~T}-1$ & Oak & 45.4 & 0.898 & $<0.006$ \\
\hline & & $95 \mathrm{~T}-1$ & Oak & 25.2 & 0.883 & $0.013 \pm 0.001$ \\
\hline & D3 & $94 \mathrm{~T}-1$ & Birch & 7.99 & 0.878 & $<0.035$ \\
\hline & & $94 \mathrm{~T}-2$ & Oak & 7.00 & 0.652 & $<0.040$ \\
\hline & & $94 \mathrm{~T}-3$ & Cowberry & 5.04 & 0.850 & $<0.056$ \\
\hline & & $94 \mathrm{~T}-4$ & Black alder & 10.0 & 0.633 & $<0.028$ \\
\hline & & $95 \mathrm{~T}-1$ & Birch & 10.0 & 0.685 & $<0.028$ \\
\hline & & $95 \mathrm{~T}-2$ & Black alder & 12.1 & 0.543 & $<0.023$ \\
\hline & & $95 \mathrm{~T}-3$ & Oak & 10.1 & 0.856 & $<0.028$ \\
\hline & & $95 \mathrm{~T}-4$ & Cowberry & 8.06 & 0.843 & $0.094 \pm 0.011$ \\
\hline
\end{tabular}

*: Replicates.

The activities of ${ }^{137} \mathrm{Cs}$ in the samples were measured with a Ge detector (Seiko EG\&G Ortec) coupled with a multi channel analyzer (Seiko EG\&G, Model 7800) before the chemical separation for ${ }^{99} \mathrm{Tc}$.

2.3. Chemical separation. A simple wet digestion method in combination with an extraction chromatographic resin separation method was applied for ${ }^{99} \mathrm{Tc}$. About $1-45 \mathrm{~g}$ portions of the plant samples were incinerated at $450{ }^{\circ} \mathrm{C}$ in an electrical oven for $2 \mathrm{~h}$ to decompose organic matter. Then, in order to obtain the recoveries of ${ }^{99} \mathrm{Tc}$, a certain amount of ${ }^{95 \mathrm{~m}} \mathrm{Tc}$ was added and they were mixed uniformly. Next Tc was extracted with $4 \mathrm{M} \mathrm{HNO}_{3}$ while heating the samples at $100{ }^{\circ} \mathrm{C}$ in a glass beaker covered with a watch glass. The residue was removed by filtration and the solution was diluted to obtain the acidity of ca. $0.1 \mathrm{M} \mathrm{HNO}_{3}$ and passed through a TEVA resin column to purify and concentrate Tc isotopes. Because ICP-MS cannot differentiate between ${ }^{99} \mathrm{Ru}$ and ${ }^{99} \mathrm{Tc}$, it is necessary to remove all $\mathrm{Ru}$ from the final sample solution prior to ICP-MS mea- surement. Ruthenium present in the sample solution is not effectively retained on the TEVA resin and passes directly through the resin, while almost all Tc is extracted on the resin. ${ }^{12}$ The column was then washed with $2 \mathrm{M} \mathrm{HNO}_{3}$ to remove any remaining trace $\mathrm{Ru}$ and other matrix elements which interfered with ${ }^{99} \mathrm{Tc}$ measurement by ICP-MS. Technetium adsorbed on the resin was eluted with $5 \mathrm{~mL}$ of $8 \mathrm{M} \mathrm{HNO}_{3}$ solution. The volume of the ${ }^{99} \mathrm{Tc}$ fraction from the TEVA column solution was reduced to near dryness $\left(<70{ }^{\circ} \mathrm{C}\right)$ and then dissolved in $5 \mathrm{~mL}$ of $2 \%$ $\mathrm{HNO}_{3}$ solution. Details of this method are in the literature. ${ }^{13}$

2.4. Measurements. Radiochemical recoveries of Tc plant samples were monitored with ${ }^{95 \mathrm{~m}} \mathrm{Tc}$ activities in the final $2 \%$ $\mathrm{HNO}_{3}$ solutions before ICP-MS measurements. The gammarays $(204 \mathrm{keV})$, was measured with a $\mathrm{NaI}(\mathrm{Tl})$ scintillation counter (Aloka, ARC-380) for $20 \mathrm{~min}$. Then the solution was introduced into an ICP-MS (Yokogawa, PMS-2000) to measure ${ }^{99} \mathrm{Tc}$ for $10 \mathrm{~min}$. The typical detection limit in solutions, calculated as three times the standard deviation of the blank, was $0.03 \mathrm{mBq} \mathrm{mL} L^{-1}$.

\section{Results and Discussion}

3.1. Technetium-99 concentrations in plant samples. Total chemical recoveries throughout the method with ${ }^{95 \mathrm{~m}} \mathrm{Tc}$ are listed in Table 1 , and they ranged from 0.48 to 0.92 with an average of 0.76 . No relation was found between sample amount and recovery. Three replicates of samples K2-94F-1 and D394G-1 were used in amounts of 1-2.6 g and 1.8-10.2 g, respectively, and there were no differences between their recoveries. However, the recoveries of two sub-samples of K2-94G-2 and D1-94G-1 differed by about 0.1 and 0.2 , respectively; when sample amounts increased, the recoveries decreased. Possibly, plant matrices, such as $\mathrm{K}, \mathrm{Ca}$ and $\mathrm{Cl}$, would affect the ${ }^{99} \mathrm{Tc}$ recovery, especially at the TEVA resin separation steps.

Technetium- 99 concentrations in all samples are also listed in Table 1 and they ranged from $<0.006$ to $6.0 \mathrm{mBq} \mathrm{g}^{-1}$. For 11 samples, especially in the Tree group, it was hard to determine ${ }^{99} \mathrm{Tc}$, because of its low concentration. Since K2 was closer to the reactor than the other 2 sites were, Fern and Herb groups showed higher ${ }^{99} \mathrm{Tc}$ concentrations in $\mathrm{K} 2$ than in $\mathrm{D} 1$ and D3. No Tree group samples were available from K2; however, we expected ${ }^{99} \mathrm{Tc}$ concentrations in tree leaves would be higher at K2 than at the other 2 sites as well, although the concentrations should be much lower than those of Fern and Herb groups.

Then, by calculating activity ratios of ${ }^{99} \mathrm{Tc}$ to ${ }^{137} \mathrm{Cs}$ in plant samples, we were able to compare uptake behavior of these elements. The results are shown in Figure 1. Previously, it was reported that the soil organic layer in these sites had ${ }^{99} \mathrm{Tc} /{ }^{137} \mathrm{Cs}$ activity ratios of between $(0.37-1.24) \times 10^{-4}$. 9 These data were based on total activity ratio; the bioavailability of ${ }^{137} \mathrm{Cs}$ should be much smaller than that of ${ }^{99} \mathrm{TcO}_{4}{ }^{-}$due to their different chemistries and fixation mechanisms by soils. Consequently, higher activity ratios in the plants than in the soils were expected if $\mathrm{Tc}$ was in $\mathrm{TcO}_{4}^{-}$. At $\mathrm{K} 2$, the activity ratios for the Fern group were lower than that for the soils, while the Herb group showed higher activity ratios than soils did. It is well known that fern plants can adsorb much more Cs than more highly evolved plants can, and this could be the reason for their low activity ratios. For the samples at D1 and K2, the ratios for the Herb group were usually about 5-10 times higher than those for the soils, that is, bioavailability of Tc at D1 and K2 sites was 5-10 times higher than that of Cs. However the Tc bioavailability was smaller than expected from their reported $\mathrm{TFs}^{3}$ since TF of Tc was 150-800 times higher than that of Cs. There was no clear magnitude difference for the Tree group and soils. On the other hand, the ratios at D3 were usually lower than those in soils for Herb and Tree groups which implied that ${ }^{99} \mathrm{Tc}$ bioavailability there was much lower than expected. The results 


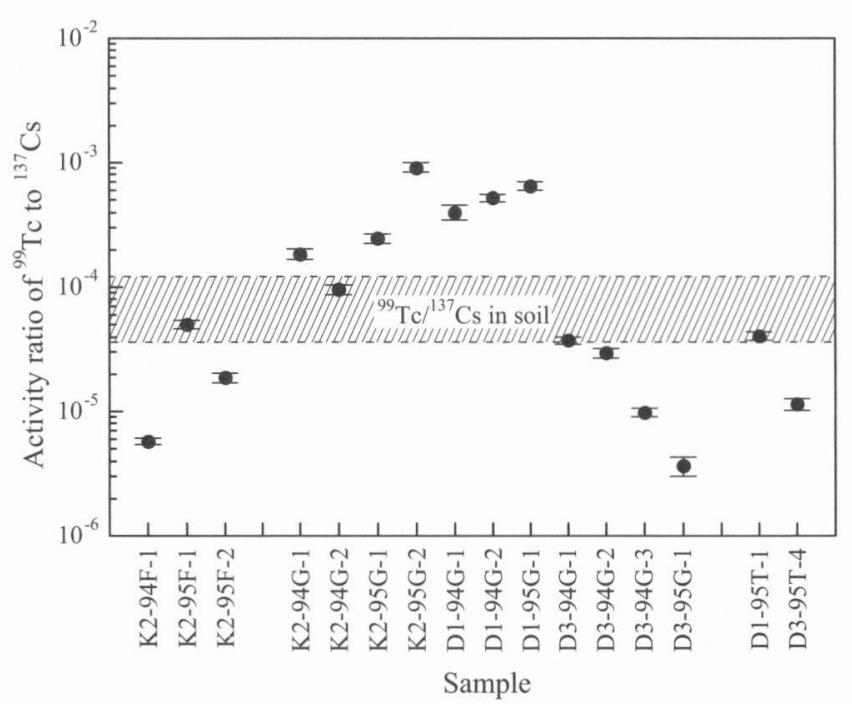

Figure 1. Activity ratio of ${ }^{99} \mathrm{Tc}$ to ${ }^{137} \mathrm{Cs}$ in plant samples collected in forests within the $30-\mathrm{km}$ zone around the Chernobyl Nuclear Power Plant. Bars show counting error (1 sigma).

suggested that most part of the Tc was not pertechnetate form.

3.2. Transfer factor for ${ }^{99} \mathrm{Tc}$. In general, $\mathrm{TF}$ is defined as the ratio of activity concentration in plant (in $\mathrm{Bq} \mathrm{g}^{-1}$ dry weight (DW)) to activity concentration in soil (in $\mathrm{Bq} \mathrm{g}^{-1} \mathrm{DW}$ ). It has been noted that forest under story plants are expected to take up radionuclides mainly from organic layers ${ }^{9}$ and therefore, concentration of ${ }^{99} \mathrm{Tc}$ in organic soil would be important for estimation of its uptake. For this reason, we calculated TFs in terms of activity concentration in a plant relative to activity concentration in organic soil. In the soils, as reported previously, ${ }^{9}$ concentrations of ${ }^{99} \mathrm{Tc}$ were $8.6 \pm 0.3 \mathrm{~Bq} \mathrm{~g}^{-1}$ in 1994 and $13.4 \pm 0.2 \mathrm{~Bq} \mathrm{~g}^{-1}$ in 1995 for $\mathrm{K} 2$ site, $1.1 \pm 0.02 \mathrm{~Bq} \mathrm{~g}^{-1}$ (combined sample from 1994 and 1995) for D1 and $2.4 \pm 0.01 \mathrm{~Bq} \mathrm{~g}^{-1}$ in 1994 and $1.72 \pm 0.05 \mathrm{~Bq} \mathrm{~g}^{-1}$ in 1995 for D3 site.

Figure 2 shows the TFs of Tc for all the samples. They ranged from $<0.016$ to 0.28 for Fern, 0.009 to 0.47 for Herb and $<0.006$ to 0.05 for Tree groups based on the ${ }^{99} \mathrm{Tc}$ contents of the organic layers. The highest TF was found in the leaves of raspberry. The observed-TFs were lower than the IAEAcompiled values of 8.1-2600 for leafy vegetables, fodder and grass $^{3}$; other reported values are as listed in Table 2. Comparing

TABLE 2: Transfer Factors for Tc Reported for Various Plants Grown in Soil

\begin{tabular}{|c|c|c|c|}
\hline Crop & TF & Conditions & Reference \\
\hline $\begin{array}{c}\text { Soybean, Leaves } \\
\text { Wheat, Blade }\end{array}$ & $\begin{array}{r}85-186 \\
312-476\end{array}$ & Silt loam, Pot & 14 \\
\hline $\begin{array}{l}\text { Herbaceous } \\
\text { vegetation }\end{array}$ & $6.7-22$ & Silt loam, Field & 15 \\
\hline Radish & $\begin{array}{c}2.1,9.5 \\
9.5,14.2\end{array}$ & $\begin{array}{l}\mathrm{pH}=5.7 \\
\mathrm{pH}=6.7\end{array}$ & \\
\hline Chard & $\begin{array}{l}2.6 \\
6.3\end{array}$ & $\begin{array}{l}\mathrm{pH}=5.7 \\
\mathrm{pH}=6.7\end{array}$ & 4 \\
\hline Turnip & $\begin{array}{l}4.5 \\
7.4\end{array}$ & $\begin{array}{c}\mathrm{pH}=5.7 \\
\mathrm{pH}=6.7 \\
>10 \mathrm{y} \text { aged, Field }\end{array}$ & \\
\hline Grass pasture mixture & 6 & 3 y Lysimeter & 5 \\
\hline Grass & $0.91-3.02$ & Reclaimed land, Field & 16 \\
\hline Green vegetables & 1.2 & Reclaimed land, Field & 17 \\
\hline Rye grass & $44-371$ & Cambisol, Pot & 18 \\
\hline $\begin{array}{c}\text { Herbaceous } \\
\text { vegetation }\end{array}$ & $0.009-0.47$ & Podzol, Peat-gley, Field & This study \\
\hline
\end{tabular}

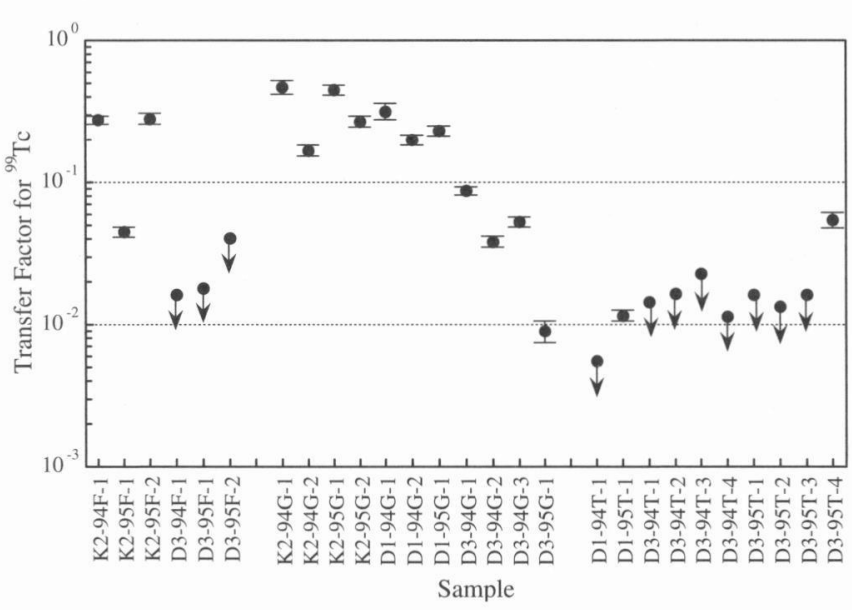

Figure 2. Soil-to-plant transfer factor of ${ }^{99} \mathrm{Tc}$ in plant samples. The ${ }^{99} \mathrm{Tc}$ concentration data are from reference 5 . Error bars show counting error (1 sigma). Arrows indicate that TFs are lower than the values estimated from the detection limit for ${ }^{99} \mathrm{Tc}$.

the TF for Tc reported for various plants grown in soil, the present results were almost the same as the data observed in reclaimed land, ${ }^{16}$ although the data from pot experiments ${ }^{14,18}$ were much higher.

From these results, we concluded Tc bioavailability in the natural environment would be lower than the bioavailabilities obtained from laboratory studies that used $\mathrm{TcO}_{4}{ }^{-}$to obtain $\mathrm{Tc}$ TFs. Previously, we observed that there are three main paths for $\mathrm{TcO}_{4}{ }^{-}$uptake by plants. ${ }^{19}$ However, no clear path has been reported for the other Tc chemical forms. It is known that the most plant-available form of $\mathrm{Tc}$ is $\mathrm{TcO}_{4}{ }^{-}$, and other forms, such as Tc-cysteine, have less availability to plants. ${ }^{20}$ Thus, as written above, $\mathrm{TcO}_{4}{ }^{-}$was not the only $\mathrm{Tc}$ chemical from in these forests. Possibly most Tc was in less soluble form, such as organically bound forms, sesquioxide bound and lower oxidation forms. ${ }^{6}$

Concerning the Herb group, the TFs were $0.17-0.47$ at $\mathrm{K} 2$, $0.20-0.32$ at D1 and $0.009-0.086$ at D3. The TFs for the samples collected at D3 were lower than those at D1 and K2. This might be due to the fact that D3 was a so-called wet forest and reducing conditions might possibly exist. The bioavailable $\mathrm{Tc}$ was presumably influenced by the soil redox conditions. Since the anaerobic condition was established by waterlogging and activity of microorganisms, Tc would be transformed from to a lower oxidation and less available form such as $\mathrm{TcO}_{2}$, $\mathrm{TcO}(\mathrm{OH})_{2}$ or $\mathrm{TcS}_{2}$ under a relatively low redox condition. Due to the relatively low redox conditions of the D3 site, the TFs were lower than those in $\mathrm{K} 2$ and D1 sites.

Thus, the low TFs we observed in this study implied that 89 years after ${ }^{99} \mathrm{Tc}$ release from the Chernobyl Nuclear Power Plant, Tc should have been transformed to insoluble or less plant-available forms. Technetium would not be in readily available form to plants in the environment.

Acknowledgements. We are grateful to Dr. W. Rühm, Ludwig Maximilians University Munich, Germany, Dr. M. Steiner, BfS -Institute of Radiation Hygiene, Germany and Dr. E. Wirth, Institute for Atmospheric Radioactivity, Germany, for providing us with the plant samples. We would like to express our deep gratitude to Dr. T. Sekine, Tohoku University, Japan, for his help in the generation of ${ }^{95 \mathrm{~m}} \mathrm{Tc}$.

\section{References}

(1)D. G. Brookins, Eh-pH Diagrams for Geochemistry (Springer-Verlag Berlin, 1988), 97-99.

(2) International Atomic Energy Agency, Generic Models and Parameters for Assessing the Environmental Transfer of 
Radionuclides from Routine Releases, Safety Series No. 57, (IAEA, Vienna, 1982).

(3) International Atomic Energy Agency, Handbook of Parameter Values for the Prediction of Radionuclide Transfer in Temperate Environments, Technical Reports Series No. 364. (IAEA, Vienna, pp 14-26, 1994).

(4) C. T. Garten, Jr, C. S. Tucker, and T. G. Scott, J. Environ. Radioactiv. 4, 91 (1986).

(5) C. M. Vandecasteele, J. P. Dehut, S. Van Laer, D. Deprins, and C. Myttenaere, Health Phys. 57, 247 (1989).

(6) K. Tagami and S. Uchida, Toxicol. Environ. Chem. 56, 235 (1996).

(7) K. Tagami and S. Uchida, Chemosphere 38, 963 (1999).

(8) K. Tagami and S. Uchida, J. Nucl. Radiochem. Sci. 3, 1 (2002).

(9) S. Uchida, K. Tagami, E. Wirth, and W. Rühm, Chemosphere 39, 2757 (1999).

(10) T. Sekine, M. Konishi, H. Kudo, K. Tagami, and S. Uchida, J. Radioanal. Nucl. Chem. 239, 483 (1999).

(11)D. Lux, L. Kammerer, W. Rühm, and E. Wirth, Sci. Total
Environ. 173/174, 375 (1995).

(12) S. Uchida and K. Tagami, J. Radioanal. Nucl. Chem. 221, 35 (1997).

(13) S. Uchida, K. Tagami, W. Rühm, M. Steiner, and E. Wirth, Appl. Radiat. Isot. 53, 69 (2000).

(14) R. E. Wildung, T. R. Garland, and D. A. Cataldo, Health Phys. 32, 314 (1977).

(15) F. O. Hoffman, C. T. Garten, Jr., D. M. Lucas, and J. W. Huckabee, Environ. Sci. Technol. 16, 214 (1982).

(16) N. Green, B. T. Wilkins, M. F. Davidson, and D. J. Hammond, J. Environ. Radioactiv. 27, 35 (1995).

(17) N. Green and B. T. Wilkins, Sci. Total Environ. 173/174, 385 (1995).

(18) G. Echevarria, J. L. Morel, L. Florentin, and E. LeclercCessac, J. Environ. Radioact. 70, 85 (2003).

(19) K. Tagami and S. Uchida, Chemosphere 60, 714 (2005).

(20) L. R. Van Loon and J. F. M. M. Lembrechts, Technetium in the Environment, edited by G. Desmet, and C. Myttenaere (Elsevier Applied Science Publicaiton, London, 1986), P. 301. 